\title{
Morphometric Analysis of Spinal Cord Dimensions of Individuals Who Are Undergoing MRI at dept of Radio- Diagnosis in HSK Hospital and Research Center, SNMC, Bagalkot
}

\author{
Chaitanya Dhotre ${ }^{1}$, Jayashree RG ${ }^{2}$, Tukaram Rathod ${ }^{3}$, Rudresh Halawar ${ }^{4}$ \\ ${ }^{1}$ Junior Resident, Department of Radio-Diagnosis, ${ }^{2}$ Professor, Department of Radio-Diagnosis, ${ }^{3}$ Assistant professor, \\ Department of Radio-Diagnosis, ${ }^{4}$ Assistant professor, Department of Radio-Diagnosis, Shri BVV Sangha's S. Nijalingappa \\ medical college, Bagalkot, Navanagar, Karnataka, India
}

Corresponding author: Dr Chaitanya Dhotre, Room No 103, PG Hostel, S.Nijalingappa Medical College, Bagalkot - 587102, Navanagar, Karnataka, India

DOI: http://dx.doi.org/10.21276/ijcmsr.2019.4.2.16

How to cite this article: Chaitanya Dhotre, Jayashree RG, Tukaram Rathod, Rudresh Halawar. Morphometric analysis of spinal cord dimensions of individuals who are undergoing MRI at dept of radio-diagnosis in HSK Hospital and research center, SNMC, Bagalkot. International Journal of Contemporary Medicine Surgery and Radiology. 2019;4(2):B71-B75.

\section{A B S T R A C T}

Introduction: The vertebral column is a part of the axial skeleton of man which has to perform particular tasks. The objective of the study was to quantitatively measure the spinal cord, regionally and segmentally so as to gather basic morphometric data in healthy population.

Material and Methods: A total of 60 healthy participants aged between 20-60 years were included in this cross-sectional study. All of them underwent MRI scan of their healthy spine after a thorough clinical examination at HSK hospital from December 2016 to May 2018.

Results: The mean age of the participants was 28 years with equal number of males and females. In the cervical segment, the AP diameter was greatest at C1 $(7.74 \mathrm{~mm}$ in males, $6.63 \mathrm{~mm}$ in females) and lowest at C7. The Transverse diameter decreased from $\mathrm{C} 1$ to $\mathrm{C} 2$ level, and then increased from C2 to C5, with C5 (12.84 mm in males and $11.55 \mathrm{~mm}$ in females) being the maximum enlarged segment and then decreased towards C7. The AP spinal canal diameter decreased from C1 to $\mathrm{C} 5$ and then gradually increased from C5 to C7. In the upper thoracic cord, the AP diameter and transverse diameter was maximum at D1 and decreased gradually from D1 to D6. In the lower thoracic cord, the AP diameter and transverse diameter was maximum at D12.

Conclusion: While assessing the spinal cord size, a single number measurement may not be enough rather each level should be compared with a set of normal values specific for that level.

Keywords: Spinal Cord, Morphometry, Segment, MRI, Antero-Posterior Diameter, Transverse Diameter, Anterior Posterior Spinal Canal Diameter

\section{INTRODUCTION}

Human spine is an interesting mechanical assemblycomplex in structure and function. Its purpose is to protect the spinal cord and nerve roots and also to provide flexibility and mobility to the main body, also ensuring access to the indispensable stimuli for the senses of sight, hearing and balance. Low back pain is a very common health problem worldwide and a major cause of disability - affecting performance at work and general well-being. Low back pain can be acute, sub-acute, or chronic. Though several risk factors have been identified (including occupational posture, depressive moods, obesity, body height and age), the causes of the onset of low back pain remain obscure and diagnosis difficult to make. In most cases, the origins remain unknown. Low back pain affects people of all ages, from children to the elderly, and is a very frequent reason for medical consultations. ${ }^{1-3}$ The 2010 Global Burden of Disease Study estimated that low back pain is among the top 10 diseases and injuries that account for the highest number of DALYs worldwide. ${ }^{4}$

The relation between abnormalities in the lumbar spine and low back pain is equivocal..$^{5}$ In case of suspicion of serious spinal pathology, diagnostic confirmation is required since delayed treatment may lead to serious adverse consequences. Previous autopsy studies, as well as myelography, computerized tomography (CT), and magnetic resonance imaging (MRI), have shown abnormalities in a substantial number of people without back pain. The major limitation of myelography is that, it provides indirect information about the details of the spinal cord ${ }^{6}$ while though, CT scan 
shows details of bony structures, its soft tissue resolutions are not satisfactory. ${ }^{7}$ Magnetic resonance imaging (MRI) of the spine is a invaluable tool for evaluation, assessment of severity and follow up of diseases of the spine. It is a very highly sensitive diagnostic test for detecting anatomic abnormalities of the spine and the adjacent structures. ${ }^{8} \mathrm{MRI}$ There is general consensus that MRI is the preferred imaging modality of choice in imaging the spinal cord as it has the advantage of not using ionising radiation and has good visualizing capacities especially of the soft tissues. Hence its use is invaluable for the detection of spinal infections, spinal metastases, nerve root disorders and disc abnormalities. ${ }^{9}$

Worldwide there is a dearth of data regarding the morphometric measurements of healthy spinal cord, particularly in developing countries like India. Quantitative measures of the dimensions of the spinal cord at various levels in normal population can provide the basis for understanding and interpreting clinical implications, such as the relationship between vertebral injury level and segment level, the morphological characteristics of the severity of spinal cord stenosis, and the possible correlation between the narrowing and symptomatic patients. Hence the present study aimed to obtain quantitative morphometric data of spinal cord both regionally and segmentally from the healthy human participants so as to understand the association between morphological abnormalities of the spinal cord and its clinical consequences.

\section{MATERIAL AND METHODS}

This cross-sectional observational study was carried out at the Department of Dept. of Radio-Diagnosis, in S N Medical College and H.S.K Hospital, Bagalkot. The study participants were patients undergoing MRI conditions other than spinal cord pathology and healthy volunteers in the study setting. A total of 60 eligible participants were consecutively recruited into the study. The study was conducted between December 2016 and May 2018.

\section{Inclusion criteria}

- Individuals of age group between 20 to 40 years undergoing MRI for conditions other than spinal pathology.

- Volunteers in the same age group.

\section{Exclusion criteria}

- Spinal cord stenosis

- Compressive Cervical Myelopathy.

- Atrophy.

- Spinal cord tumors.

- Patients with spinal injury.

- Individuals with incidentally detected spinal pathology during the MRI scan.

- Pregnancy.

Study was approved by institutional human ethics committee. Informed written consent was obtained from all the study participants and only those participants willing to sign the informed consent were included in the study. The risks and benefits involved in the study and voluntary nature of participation were explained to the participants before obtaining consent. Confidentiality of the study participants was maintained.

\section{Data collection tools and methods}

All the relevant parameters were documented in a structured study proforma. After obtaining the informed written consent form all the study subjects were evaluated by detailed clinical examination of the spinal cord. Dimensions of the multiple segments of human spinal cord are measured in AP (antero-posterior) and transverse diameter of spinal cord and AP (antero-posterior) diameter of spinal canal at each level by high resolution T2-weighted images acquired by $1.5 \mathrm{~T}$ Philips MR System Achieva.

\section{STATISTICAL ANALYSIS}

Spinal cord dimensions were outcome parameters. All Quantitative variables were checked for normal distribution within each category of explanatory variable by using visual inspection of histograms and normality Q-Q plots. ShapiroWilk test was also conducted to assess normal distribution. Shapiro-Wilk test $\mathrm{p}$ value of $>0.05$ was considered as normal distribution. Descriptive analysis was carried out by mean and standard deviation for quantitative variables, frequency and proportion for categorical variables. For normally distributed Quantitative parameters (Spinal cord dimensions) the mean values were compared between males and females using Independent sample t-test ( 2 groups). $\mathrm{P}$ value of $<0.05$ was considered statistically significant. IBM SPSS version 22 was used for statistical analysis.

\section{RESULTS}

The mean of age of the participants was $28.03 \pm 5.75$ years with a minimum age of 20 years and a maximum age of 40 years. Majority of them (41:68.33\%) were aged up to 30 years with the remining (19:31.67\%) aged between 31 to 40 years. Genderwise males and females were in equal proportion (Table 1).

Table 2 describes the gender wise mean AP measurements of cervical cord. At $\mathrm{C} 1$ level in males, it was $7.74 \pm 0.75$, it was $6.63 \pm 0.73$ for females. The mean of AP at C2 level in males was $7.49 \pm 0.67$, it was $6.59 \pm 0.65$ for females. The mean of $\mathrm{AP}$ at $\mathrm{C} 3$ level in males was $7.1 \pm 0.72$, it was $6.6 \pm 0.65$ for females. The mean of AP at $\mathrm{C} 4$ level in males was 6.78 \pm 0.92 , it was $6.4 \pm 0.51$ for females. The mean of AP at $\mathrm{C} 5$ level in males was $6.64 \pm 0.86$, it was $6.49 \pm 0.59$ for females. The mean of AP at C6 level in males was $6.32 \pm 0.7$, it was $6.24 \pm 0.43$ for females. The mean of AP at C7 level in males was $5.91 \pm 0.63$, it was $5.94 \pm 0.38$ for females. The mean of average cervical cord anterior posterior diameter in males was $6.85 \pm 0.53$ and it was $6.41 \pm 0.38$ for females. There was no statistically significant difference in AP at C4, C5, $\mathrm{C} 6, \mathrm{C} 7$ between males and females. $(\mathrm{P}$ value $>0.05)$. There was statistically significant difference C1-AP, C2-AP, C3-AP, average cervical cord anterior posterior diameter between males and females. ( $\mathrm{P}$ value $<0.05)$.

Table 3 describes the gender wise comparison of the anteroposterior diameter of the upper and lower dorsal cord. At D1 level in males was $6.11 \pm 0.67$, it was $5.89 \pm 0.53$ for females. The mean of AP at D2 level in males was $5.98 \pm 0.7$, it was $5.8 \pm 0.51$ for females. The mean of AP at D3 level in males was $5.86 \pm 0.77$, it was $5.73 \pm 0.34$ for females. The mean of 
$\mathrm{AP}$ at $\mathrm{D} 4$ level in males was $5.88 \pm 0.64$, it was $5.7 \pm 0.41$ for females. The mean of AP at D5 level in males was $5.74 \pm$

\begin{tabular}{|l|c|}
\hline Parameter & Frequency \\
\hline Age & $28.03 \pm 5.75$ \\
\hline Age group & $41(68.33 \%)$ \\
\hline Up to 30 years & $19(31.67 \%)$ \\
\hline 31 to 40 years & $30(50.0 \%)$ \\
\hline Gender & $30(50.0 \%)$ \\
\hline Male & $\begin{array}{r}\text { Female } \\
\text { Table-1: Descriptive analysis of age and gender in the study } \\
\text { population (N=60) }\end{array}$ \\
\hline
\end{tabular}

0.71 , it was $5.65 \pm 0.39$ for females. The mean of AP at D6 level in males was $5.69 \pm 0.6$, it was $5.61 \pm 0.42$ for females. The mean of average Upper dorsal cord anterior posterior diameter in males was $5.87 \pm 0.48$ and it was $5.73 \pm 0.30$ for females. There was no statistically significant difference in AP at D1, D2, D3, D4, D5, D6 and average AP levels between males and females. ( $P$ value $>0.05$ ).

The mean of Lower dorsal cord AP at D7 level in males was $5.72 \pm 0.63$, it was $5.45 \pm 0.39$ for females. The mean of AP at D8 level in males was $5.9 \pm 0.82$, it was $5.59 \pm 0.38$ for females. The mean of AP at D9 level in males was $6.25 \pm$ 0.72 , it was $5.77 \pm 0.63$ for females. The mean of AP at D10 level in males was $5.98 \pm 0.71$, it was $5.77 \pm 0.55$ for females. The mean of AP at D11 level in males was $6.56 \pm 1$, it was

\begin{tabular}{|l|c|c|c|c|c|c|c|}
\hline \multirow{2}{*}{ Cervical cord transverse diameter } & \multicolumn{3}{|c|}{ Male } & \multicolumn{3}{c|}{ Female } & P value \\
\cline { 2 - 9 } & Mean \pm SD & Min & Max & Mean \pm SD & Min & Max & \\
\hline C1 & $11.63 \pm 0.82$ & 9.90 & 13.20 & $10.82 \pm 0.85$ & 9.60 & 12.40 & $<0.001$ \\
\hline C2 & $11.5 \pm 0.82$ & 9.40 & 12.90 & $10.61 \pm 0.76$ & 9.40 & 12.20 & $<0.001$ \\
\hline C3 & $11.94 \pm 0.95$ & 9.80 & 13.60 & $11.1 \pm 0.88$ & 9.20 & 13.30 & 0.001 \\
\hline C4 & $12.76 \pm 1.04$ & 10.70 & 14.80 & $11.31 \pm 0.98$ & 9.60 & 13.20 & $<0.001$ \\
\hline C5 & $12.84 \pm 0.93$ & 11.40 & 15.60 & $11.55 \pm 1.05$ & 9.80 & 13.40 & $<0.001$ \\
\hline C6 & $12.45 \pm 1.26$ & 9.90 & 15.00 & $11.21 \pm 0.87$ & 9.50 & 13.20 & $<0.001$ \\
\hline C7 & $10.78 \pm 1.26$ & 7.60 & 14.80 & $10.56 \pm 1.09$ & 7.90 & 13.30 & 0.486 \\
\hline Average & $11.98 \pm 0.72$ & 10.33 & 13.66 & $11.02 \pm 0.76$ & 9.81 & 12.81 & $<0.001$ \\
\hline \multicolumn{7}{|c|}{} & \multicolumn{7}{|c|}{ Table-2: Comparison of Cervical cord transverse diameter between males and females (N=60) } \\
\hline
\end{tabular}

\begin{tabular}{|c|c|c|c|c|c|c|c|}
\hline \multirow[t]{2}{*}{ Parameter } & \multicolumn{3}{|c|}{ Male } & \multicolumn{3}{|c|}{ Female } & \multirow[t]{2}{*}{$P$ value } \\
\hline & Mean \pm SD & Min & Max & Mean \pm SD & Min & Max & \\
\hline \multicolumn{8}{|c|}{ Upper dorsal cord anterior posterior diameter } \\
\hline $\mathrm{D} 1$ & $6.11 \pm 0.67$ & 5.00 & 7.00 & $5.89 \pm 0.53$ & 4.80 & 7.00 & 0.155 \\
\hline D2 & $5.98 \pm 0.7$ & 4.50 & 7.10 & $5.8 \pm 0.51$ & 4.60 & 6.90 & 0.269 \\
\hline D3 & $5.86 \pm 0.77$ & 4.50 & 7.20 & $5.73 \pm 0.34$ & 5.10 & 6.30 & 0.388 \\
\hline D4 & $5.88 \pm 0.64$ & 4.70 & 7.20 & $5.7 \pm 0.41$ & 5.00 & 6.60 & 0.199 \\
\hline D5 & $5.74 \pm 0.71$ & 4.50 & 7.50 & $5.65 \pm 0.39$ & 5.00 & 6.50 & 0.530 \\
\hline D6 & $5.69 \pm 0.6$ & 4.60 & 6.70 & $5.61 \pm 0.42$ & 4.90 & 6.60 & 0.588 \\
\hline Average & $5.87 \pm 0.48$ & 5.05 & 6.77 & $5.73 \pm 0.30$ & 4.97 & 6.18 & 0.167 \\
\hline \multicolumn{8}{|c|}{ Lower dorsal cord anterior posterior diameter } \\
\hline D7 & $5.72 \pm 0.63$ & 4.10 & 7.40 & $5.45 \pm 0.39$ & 5.00 & 6.30 & 0.048 \\
\hline D8 & $5.9 \pm 0.82$ & 4.60 & 7.80 & $5.59 \pm 0.38$ & 5.00 & 6.40 & 0.065 \\
\hline D9 & $6.25 \pm 0.72$ & 4.70 & 8.00 & $5.77 \pm 0.63$ & 5.00 & 8.10 & 0.008 \\
\hline D10 & $5.98 \pm 0.71$ & 5.00 & 7.80 & $5.77 \pm 0.55$ & 5.00 & 7.10 & 0.026 \\
\hline D11 & $6.56 \pm 1$ & 5.20 & 8.40 & $6.04 \pm 0.74$ & 5.10 & 8.20 & 0.011 \\
\hline D12 & $7 \pm 1.16$ & 4.30 & 9.20 & $5.88 \pm 0.81$ & 5.00 & 7.50 & 0.001 \\
\hline Average & $6.3 \pm 0.52$ & 5.65 & 7.60 & $5.75 \pm 0.32$ & 5.12 & 6.55 & $<0.001$ \\
\hline
\end{tabular}

\begin{tabular}{|c|c|c|c|c|c|c|c|}
\hline \multirow{2}{*}{$\begin{array}{l}\text { Lower dorsal cord transverse diameter } \\
\text { transverse diameter }\end{array}$} & \multicolumn{3}{|c|}{ Male } & \multicolumn{3}{|c|}{ Female } & \multirow[t]{2}{*}{$P$ value } \\
\hline & Mean \pm SD & Min & Max & Mean \pm SD & Min & Max & \\
\hline D7 & $7.74 \pm 0.83$ & 6.70 & 10.60 & $8.11 \pm 1.03$ & 6.20 & 9.90 & 0.132 \\
\hline D8 & $7.54 \pm 0.74$ & 6.30 & 9.60 & $7.98 \pm 1.08$ & 6.00 & 10.60 & 0.068 \\
\hline D9 & $7.72 \pm 0.7$ & 6.20 & 9.00 & $7.69 \pm 1.03$ & 5.70 & 9.80 & 0.895 \\
\hline D10 & $8.19 \pm 0.87$ & 6.50 & 10.40 & $7.67 \pm 0.96$ & 6.10 & 9.20 & 0.088 \\
\hline D11 & $8.24 \pm 0.92$ & 5.40 & 10.00 & $8.06 \pm 0.84$ & 6.70 & 9.60 & 0.465 \\
\hline $\mathrm{D} 12$ & $8.51 \pm 1.76$ & 5.20 & 12.20 & $8.45 \pm 1.19$ & 6.50 & 10.70 & 0.971 \\
\hline Average & $7.96 \pm 0.58$ & 6.95 & 9.23 & $7.98 \pm 0.80$ & 6.43 & 9.67 & 0.088 \\
\hline
\end{tabular}


$6.04 \pm 0.74$ for females. The mean of AP at D12 level in males was $7 \pm 1.16$, it was $5.88 \pm 0.81$ for females. The mean of average Lower dorsal cord anterior posterior diameter in males was $6.3 \pm 0.52$ and it was $5.75 \pm 0.32$ for females. There was statistically significant difference in Lower dorsal cord AP at D7, D9, D10, D11, D12, and average AP levels between males and females. $(P$ value $<0.05)$. There was no statistically significant difference in $\mathrm{AP}$ at $\mathrm{D} 8$ and average AP levels between males and females. $(P$ value $>0.05)$.

Table 4 describes gender wise comparison of transverse diameter of lower dorsal cord. At D7 level in males it was $7.74 \pm 0.83$, it was $8.11 \pm 1.03$ for females. The mean of TR at D8 level in males was $7.54 \pm 0.74$, it was $7.98 \pm 1.08$ for females. The mean of TR at D9 level in males was $7.72 \pm 0.7$, it was $7.69 \pm 1.03$ for females. The mean of TR at D10 level in males was $8.19 \pm 0.87$, it was $7.67 \pm 0.96$ for females. The mean of TR at D11 level in males was $8.24 \pm 0.92$, it was 8.06 \pm 0.84 for females. The mean of TR at D12 level in males was $8.51 \pm 1.76$, it was $8.45 \pm 1.19$ for females. The mean of average Lower dorsal cord transverse diameter in males was $7.96 \pm 0.58$ and it was $7.98 \pm 0.80$ for females. There was no statistically significant difference in lower dorsal cord TR at D7, D8, D9, D10, D11, D12 and average levels between males and females.(P value $>0.05)$.

\section{DISCUSSION}

Human spine is an important part of human skeleton that consists of a column of 26 bones in the adult body and serves the major function of flexibility and mobility to the human body. It also houses and protects the spinal cord and the nerve roots. The spinal cord transmits the weight of the upper body to the pelvis when it is subjected to internal stresses that may exceed many times the entire body weight of the person. The spinal cord is often subjected to various problems like back pains and injuries. From the clinicians' point of view, the most important pathology involving spinal bony canal is spinal stenosis.

MRI has offered the clinicians with a non-invasive mechanism for viewing cervical, thoracic and lumbosacral anatomy in great details and thus preferred over CT scan and plain radiography. Therefore, studying spinal lesions with MRI will help the health care team and policy maker appreciate the common lesions and extent of radiologically detectable conditions for the purpose of proper treatment/ intervention, rehabilitation and prevention.

The determination of pattern of spinal abnormalities on MRI studies and common findings in India with particular emphasis on the commonly requested MRI examinations is the need of the hour. There is also the necessity to show how sensitive MRI is in detecting spinal abnormality in symptomatic cases. We conducted the study with an intention to gather basic quantitative morphometric data of healthy human spinal cord both regionally and segmentally that can enable us to understand the morphological abnormalities and the clinical consequences of spinal cord.

\section{Cervical cord parameters}

Antero-posterior diameter

A narrow osseous cervical canal is often encountered in the lower segment of the morphologic range of the normal population. Although this so-called "developmental spinal stenosis" is usually asymptomatic, it may not only exacerbate the onset and degree of the soft tissue degenerative hypertrophies characteristic of the acquired cervical stenoses, but may, in itself, predispose the neuropraxy of the cervical spinal cord seen in sport traumas. ${ }^{10-12}$

In our study, the AP diameter of spinal cord was greatest at $\mathrm{C} 1$ and it gradually decreased from $7.74 \mathrm{~mm}$ at $\mathrm{C} 1$ in males and $6.63 \mathrm{~mm}$ in females with the lowest at $\mathrm{C} 7$ vertebrae. This finding was in line with that of Frostell $\mathrm{A}$ et $\mathrm{al}^{13}$ who also observed that the AP diameter was greatest at $\mathrm{C} 1(8.3 \mathrm{~mm})$ and gradually decreased till $\mathrm{C} 7(6.9 \mathrm{~mm})$. In the present study, however, gender wise there was statistically significant difference between the AP diameters at $\mathrm{C} 1, \mathrm{C} 2$ and $\mathrm{C} 3(\mathrm{P}$ value $<0.05$ ) and not between that of $\mathrm{C} 4, \mathrm{C} 5, \mathrm{C} 6$ an $\mathrm{C} 7$. In a study among healthy people Fang $\mathrm{JH}$ et $\mathrm{al}^{14}$ noted that the diameters of cervical spinal cord was larger in the males than in the females, decreased with age, and increased with the length of C-spine.

\section{Transverse diameter}

In their MRI study on 66 healthy participants, Sherman et al. ${ }^{15}$ found that the transverse diameter of cervical cord was $12.4 \mathrm{~mm}$ at $\mathrm{C} 2,14 \mathrm{~mm}$ at $\mathrm{C} 4$ and $11.4 \mathrm{~mm}$ at $\mathrm{C} 7$ with cervical enlargement noted between $\mathrm{C} 4$ and C6. Frostell A et $\mathrm{al}^{13}$ in their study observed that the spinal cord had the largest transverse diameter at spinal cord neuronal segment C5 $(13.3 \mathrm{~mm} \pm 2.2)$. Ko HY et $\mathrm{al}^{16}$ in their study on post mortem subjects also observed that the transverse diameter was largest at segment C5 (11.6 mm). Similarly, in our study the transverse diameter was largest $\mathrm{C} 5$ where in it increased from $\mathrm{C} 2$ to $\mathrm{C} 5$ while it was decreased at $\mathrm{C} 1$ and $\mathrm{C} 2$.

\section{Thoracic cord}

The AP diameter of upper thoracic cord was maximum at D1 (6.11) while it decreased gradually from D1 to D6. The transverse diameter was also maximum at D1 $(9.7 \mathrm{~mm}$ ) while it decreased gradually from D1 to D6. In comparison Frostell $\mathrm{A}$ et $\mathrm{al}^{13}$ observed that the maximum transverse (6.9 $\mathrm{mm}$ ) and AP diameter was observed at D1(10.7 mm).

The AP diameter of lower thoracic cord was maximum at D12 and there was statistically significant difference in AP diameter at D7, D9, D10, D11, D12 between males and females. ( $\mathrm{P}$ value<0.05). But Frostell $\mathrm{A}$ et $\mathrm{al}^{13}$ in their study observed that the maximum transverse $(8.6 \mathrm{~mm})$ and AP diameter was observed at D9 and D10 $(6.5 \mathrm{~mm})$. They also observed there was not a specific increasing or decreasing pattern with respect to these diameters in lower thoracic cord. Additionally in our study the Lower dorsal cord anterior posterior spinal canal diameter increased from D10 to D12 in our study.

Repeated population measurements transverse and anteroposterior diameters of the spinal cord across various subgroups could be useful in diagnosing and monitoring patients with neurodegenerative and neuroinflammatory diseases. Cervical or thoracic spinal stenosis can cause both root and/or cord compression, resulting in pain, radiculopathy, myelopathy, or myeloradiculopathy. ${ }^{17-20}$ Patients suffering from multiple sclerosis have a reduced cross-sectional area 
compared to healthy matched controls. ${ }^{21} \mathrm{~W}$ ithout population estimates, it can be difficult to determine whether a specific patient should be considered to have a pathologically small or large spinal cord.

\section{CONCLUSION}

The findings of the study showed that in the cervical segment, the AP diameter of spinal cord (neuronal segment) was greatest at $\mathrm{C} 1(7.74 \mathrm{~mm}$ in males) and lowest at C7 (6.63 $\mathrm{mm}$ in females). The Transverse diameter decreased from $\mathrm{C} 1$ to $\mathrm{C} 2$, and then increased from $\mathrm{C} 2$ to $\mathrm{C} 5$, with $\mathrm{C} 5$ being the maximum enlarged segment transversely and then decreased towards C7. The Transverse diameter at C5 level in males was $12.84 \mathrm{~mm}$ while it was $11.55 \mathrm{~mm}$ for females. In the lower thoracic cord, Both AP and transverse diameter of lower thoracic cord was maximum at D12. However, it should be noted that a single number cannot be used as the basis for evaluating spinal cord size. Each level should be compared with the normal range specific for that level.

\section{REFERENCES}

1. Balague F, Troussier B, Salminen J. Non-specific low back pain in children and adolescents: risk factors. European spine journal. 1999;8(6):429-38.

2. Powell M, Szypryt P, Wilson M, Symonds E, Worthington B. Prevalence of lumbar disc degeneration observed by magnetic resonance in symptomless women. The Lancet. 1986;328(8520):1366-7.

3. Rubin DI. Epidemiology and risk factors for spine pain. Neurologic clinics. 2007;25(2):353-71.

4. Vos T, Flaxman AD, Naghavi M, Lozano R, Michaud C, Ezzati M, et al. Years lived with disability (YLDs) for 1160 sequelae of 289 diseases and injuries 1990-2010: a systematic analysis for the Global Burden of Disease Study 2010. The lancet. 2012;380(9859):2163-96.

5. Boden SD, McCowin P, Davis D, Dina T, Mark A, Wiesel S. Abnormal magnetic-resonance scans of the cervical spine in asymptomatic subjects. A prospective investigation. The Journal of bone and joint surgery American volume. 1990;72(8):1178-84.

6. Liu J, Napolitano JT, Ebraheim NA. Systematic review of cervical pedicle dimensions and projections. Spine. 2010;35(24):E1373-80.

7. Ruofu Z, Huilin Y, Xiaoyun H, Xishun H, Tiansi $\mathrm{T}$, Liang $\mathrm{C}$, et al. CT evaluation of cervical pedicle in a Chinese population for surgical application of transpedicular screw placement. Surg Radiol Anat. 2008;30(5):389-96.

8. Bican O, Minagar A, Pruitt AA. The spinal cord: a review of functional neuroanatomy. Neurol Clin. 2013;31(1):1-18.

9. Elders LA, Burdorf A. Prevalence, incidence, and recurrence of low back pain in scaffolders during a 3-year follow-up study. Spine. 2004;29(6):E101-6.

10. Torg JS, Pavlov H, Genuario S, Sennett B, Wisneski RJ, Robie B, et al. Neurapraxia of the cervical spinal cord with transient quadriplegia. The Journal of bone and joint surgery American volume. 1986;68(9):1354-70.

11. Bey T, Waer A, Walter FG, Fryburg K, Smith W. Spinal cord injury with a narrow spinal canal: utilizing Torg's ratio method of analyzing cervical spine radiographs.
The Journal of emergency medicine. 1998;16(1):79-82.

12. Torg JS, Corcoran TA, Thibault LE, Pavlov H, Sennett BJ, Naranja RJ, et al. Cervical cord neurapraxia: classification, pathomechanics, morbidity, and management guidelines. Journal of neurosurgery. 1997;87(6):843-50.

13. Frostell A, Hakim R, Thelin EP, Mattsson P, Svensson M.A Review of the Segmental Diameter of the Healthy Human Spinal Cord. Front Neurol. 2016;7(3):238.

14. Fang JH,Jia LS, Zhou XH, Chen XS, Zhang Y. [Sagittal diameters measurements on MR of the cervical spinal cord in normal subjects]. Zhonghua Wai Ke Za Zhi. 2008;46(21):1642-4.

15. Sherman JL, Nassaux PY, Citrin CM. Measurements of the normal cervical spinal cord on MR imaging. AJNR Am J Neuroradiol. 1990;11(2):369-72.

16. Ko HY, Park JH, Shin YB, Baek SY. Gross quantitative measurements of spinal cord segments in human. Spinal Cord. 2004;42(1):35-40.

17. Kettler A, Werner K, Wilke HJ. Morphological changes of cervical facet joints in elderly individuals. Eur Spine J. 2007;16(7):987-92.

18. Kayalioglu G, Erturk M, Varol T, Cezayirli E. Morphometry of the cervical vertebral pedicles as a guide for transpedicular screw fixation. Neurol Med Chir (Tokyo). 2007;47(3):102-7.

19. Singh R, Srivastva SK, Prasath CS, Rohilla RK, Siwach R, Magu NK. Morphometric measurements of cadaveric thoracic spine in Indian population and its clinical applications. Asian Spine J. 2011;5(1):20-34.

20. Wang TM, Shih C. Morphometric variations of the lumbar vertebrae between Chinese and Indian adults. Acta Anat (Basel). 1992;144(1):23-9.

21. Kearney H, Miller DH, Ciccarelli O. Spinal cord MRI in multiple sclerosis--diagnostic, prognostic and clinical value. Nat Rev Neurol. 2015;11(6):327-38.

Source of Support: Nil; Conflict of Interest: None

Submitted: 30-04-2019; Accepted: 21-05-2019; Published online: 03-06-2019 